\title{
Formation of the organizational and legal mechanism for ensuring environmental safety in the Russian Federation: problems and solutions
}

\author{
Andrey Vorontsov ${ }^{1}$, Elena Vorontsova ${ }^{1}$, Yuriy Drozdenko ${ }^{2}$, and Ulugbek Mannanov ${ }^{3}$ \\ ${ }^{1}$ Southwest State University (SWSU) 94, 50 Let Oktyabrya Street, Kursk, 305040, Russia \\ ${ }^{2}$ T.F. Gorbachev Kuzbass State Technical University (KuzSTU), 28 Vesennyaya st., Kemerovo, \\ 650000, Russia \\ ${ }^{3}$ Tashkent State Technical University (TSTU), 2, University str., 100095, Tashkent Almazar, \\ Uzbekistan
}

\begin{abstract}
The article is a study of the process of formation of the organizational and legal mechanism for ensuring environmental safety in the Russian Federation, as well as an analysis of a number of urgent problems arising in the implementation of the state environmental policy by the country. The authors' study is interdisciplinary in nature and includes not only a legal analysis of regulatory acts adopted by the Russian state in order to ensure environmental safety, but also some assessments of an economic and natural-scientific (environmental) nature related to the functioning of resource-extracting sectors of Russian industry and their impact on state of the environment. Considerable attention is paid to the worldview aspects of the topic under study. The role of the territories of the Russian Federation not disturbed by economic activity in maintaining the sustainability of the global ecosystem is emphasized.
\end{abstract}

\section{Introduction}

At present, the ecological situation in much of Russia can be described as unfavorable. The coronavirus pandemic, the aggravation of political and economic contradictions, the fall in hydrocarbon prices somehow pushed into the background the topic of environmental safety, previously widely discussed in the global information space (Greta Tunberg's emotional statements should not be taken into account in this case, since they have nothing in common with real activities to ensure environmental safety). Meanwhile, this problem has not disappeared; it is still our companion, threatening the future of all mankind. Moreover, today many threats are based on the environmental component, as they are the result of deep changes in the natural environment of a person. It is environmental changes that fundamentally transform the lifestyle of various ethnic groups, provoking social and political conflicts, forced migration of a huge number of people, and outbreaks of certain diseases. Thus, the solution of a number of other problems that are perceived by most societies without any connection with the environment, but which are a natural result of its degradation, often depends on solving an environmental problem. 
We regret to admit that at present, attempts to create a really working mechanism for ensuring global environmental safety encounter a lack of understanding by some countries of the severity of the environmental problem, a desire to use this topic in their own interests, and a reluctance to change technological approaches to the development of natural resources. In general, the assessment of this problem in the public mind clearly lags behind the degree of its real state. In addition, imbalances in the economic development of states, which do not allow "third world countries" to fully participate in large-scale environmental measures, impede the development of a single mechanism for ensuring environmental safety.

The above circumstances compel interested states to solve the environmental problem on their own, especially since in different regions of the globe this problem manifests itself with varying degrees of intensity. Moreover, the environmental well-being of neighboring territories often depends on the success of their actions in this direction, since the biosphere, as you know, does not know state borders. Similarly, negative environmental consequences resulting from anthropogenic impacts on nature in one of the countries can go far beyond its borders, creating intractable problems for neighbors.

The Russian Federation is forced to take into account both of the above circumstances in its environmental protection activities. Its territorial borders are the longest in the world and go immediately to several climatic zones, each of which has a significant (sometimes decisive) effect not only on individual regions, but also on the planet as a whole. A significant part of the territory of Russia itself (primarily the regions of Siberia, the Far East and the Arctic) represents the last ecological reserve of mankind, and the task of our country is to save it for future generations. The problem is that these territories are currently undergoing active industrial development, and, accordingly, the anthropogenic load on them increases significantly, reaching critical values in such regions as the Kuzbass, Norilsk industrial region, and Yamal.

All this facts actualizes the need to implement state policy aimed at ensuring the environmental safety of the Russian Federation, and suggesting, first of all, reducing the harmful effects on the nature of the main resource-extracting sectors (oil, gas, mining), since it is their combined impact that causes the environment the most damage. We need a new mechanism of interaction (put forward by the authors) with nature, based on maintaining the biosphere balance and the integrated perception of all factors that can upset this balance. Only such an approach will ensure our country sustainable development in the face of a decrease in the ecological capacity of the natural environment and the need to build economic potential that ensures social progress.

In this regard, interdisciplinary studies are becoming extremely popular, allowing to analyze the problems of environmental safety from the standpoint of different branches of scientific knowledge. It is this approach that is, in our opinion, the most promising, since it allows you to take into account the maximum number of problematic aspects of this topic and characterize it most comprehensively.

The purpose of this article was to study the process of forming the organizational and legal mechanism for ensuring environmental safety in Russia, as well as to analyze some of the problems that arise in the implementation of state environmental policy.

\section{Materials and methods}

The interdisciplinary nature of this study led to the applied methodology, the basis of which was made by the methods of logical and system-functional analysis, the formal legal method, the statistical method, and the hypothesis method. In general, our study of the organizational and legal problems of ensuring environmental safety in the Russian Federation was based on the principles of science, objectivity (impartiality), and the 
relationship of the phenomena studied. The main material for the study was a wide range of programmatic strategic documents of the Russian state, federal laws and by-laws.

\section{Results and discussion}

The formation of the organizational and legal mechanism for ensuring environmental safety in Russia began with the adoption of Federal Law of 10.01.2002 №7-FZ "On Environmental Protection" [1]. In this law environmental safety was formalized as a legal phenomenon, having received its normative definition. The legislator defined environmental safety as a state of protection of the natural environment and vital human interests from the possible negative effects of economic and other activities, natural and man-made emergencies, their consequences (Article 1 of the Federal Law "On Environmental Protection") [1]. Ensuring environmental safety was proclaimed as one of the goals of state policy in the field of environmental protection, which largely determined the vector of development of environmental legislation in subsequent years.

The ideological and legal basis of this policy was constitutional provisions guaranteeing the citizens of the Russian Federation the right to a favorable environment, to reliable information about its condition, to compensation for damage caused by an environmental violation (Article 42 of the Constitution of the Russian Federation) [2]. These state legal obligations predetermined the principles of ensuring environmental safety, among which the principle of protection, reproduction and rational use of natural resources as the necessary conditions for ensuring a favorable environment and environmental safety are the main ones; the principle of responsibility of state authorities and local self-government for ensuring a favorable environment and environmental safety; the principle of presumption of environmental hazard of planned economic and other activities (Article 3 of the Federal Law "On Environmental Protection") [1]. The last of these principles is, in our opinion, of particular - extremely urgent importance in the context of the need to accelerate the socioeconomic development of our country, which involves active industrial expansion in territories that have not yet been disturbed by economic activity (the area of such territories, according to the information of the former head of the Ministry of Natural Resources of the Russian Federation S. Donskoy, is more than 11 million square meters. kilometers [3]. A simple calculation suggests that this is $53 \%$ of the territory of our country), but we will talk about this later. In the meantime, we note that following the adoption of the Federal Law "On Environmental Protection" by the Russian government, the Ecological Doctrine of the Russian Federation [4] (hereinafter referred to as the Doctrine) was approved - a strategic document that determined the goals of the state policy in the field of ecology, as well as the main directions of activities to ensure environmental security.

Functionally, the Doctrine was intended to become a guideline for all subsequent legislative work on the formation of the organizational and legal mechanism for ensuring environmental safety: environmental safety itself was declared a strategic goal of state policy, and rulemaking (based on the directions for ensuring environmental safety specified in the Doctrine) should contribute to the potential environmental safety hazardous activities, rehabilitation of territories and water areas, settlements who suffered as a result of anthropogenic impact on the environment; improving the quality of life and public health by reducing the adverse effects of environmental factors; minimization of environmental risks for the environment and public health associated with the occurrence of emergency situations of natural and man-made nature; the prevention of terrorist acts causing environmental degradation and environmental degradation; organization of control over the use and distribution of alien species and genetically modified organisms in the country [4]. In addition, the Doctrine called the principle of state environmental policy, which, in our opinion, is fundamental to the development of a new system of relationships in the "man- 
nature" system - the priority of the life-supporting functions of the biosphere with respect to the use of natural resources [4]. In our opinion, this testifies to the already occurring worldview of a certain part of the Russian elite (political, scientific, entrepreneurial) in the direction of an objective understanding of the depth of the environmental crisis that hit our country and the rest of the world, and the need to change the economic model based on the unbridled exploitation of nature .

Unfortunately, such changes in worldview did not occur in everyone. Even now, a significant part of politicians, representatives of business structures, and ordinary citizens are dominated by ideas based on a purely consumer attitude to the nature around us and its resources. In this regard, plans for large-scale mining of minerals in territories that are currently virtually unbroken by economic activities (as we mentioned above) - the taiga regions of Siberia and the Far East, the Arctic shelf, islands of the Arctic seas, cause great concern. Indeed, the explored mineral reserves in these areas are huge: $64 \%$ of coal resources are concentrated in Siberia, another 30\% - in the Far East [5]; the majority of Russian hydrocarbon deposits are concentrated in the Arctic. Prospective for oil and gas recognized $43 \%$ of the Arctic zone, including $71 \%$ of the shelf area $[6,210]$. However, it should be remembered that these territories support the necessary quality of the environment, its sustainability and biodiversity. Inevitable as a result of industrial activity, the reduction of such territories will lead to the disruption of the existing natural balance [6, 190-191], and in some cases to the onset of irreversible harmful consequences for ecological systems (it suffices to recall the Kola Peninsula, the Novaya Zemlya archipelago and other similar territories).

In addition, the experience of industrial development in Siberia, the Far East and the Arctic indicates that active production activities in these areas have an extremely negative effect on the demographics of the indigenous population living there [6]. Indigenous peoples are much more difficult to tolerate the effects of environmental changes under the influence of anthropogenic pressure, since traditional crafts and the conditions of their existence are of vital importance to them.

Global environmental concerns should also be considered. In this case, we mean the problems of "global warming", the "ozone layer" and a number of others. In this regard, the territories of the north of Russia and the Arctic that were not disturbed during industrial activity are, according to scientists, a guarantee of minimizing the dangerous consequences of planetary climate changes. It should be borne in mind that the wetlands of our country are cold carbon traps (causing the greenhouse effect), and this is extremely important for stabilizing the climate throughout the Northern Hemisphere (let's not forget that the area of such regions in Russia is about $60 \%$ of all such territories in the Northern Hemisphere).

In the context of the foregoing, we draw the attention of readers to the fact that in no case do we oppose the use of our country's natural resources. Their development is objectively determined by the objectives of the development of our society, implying the creation of a powerful economic base, including resource-mining. However, the methods of this development, approaches to the implementation of economic activity in territories that are extremely vulnerable from the point of view of ecology (and our resource "storeroom" is located precisely on such), in our deep conviction, should fundamentally differ from those that our country used in the $70 \mathrm{~s}$. XX century - the period of active industrial development of Siberia and the Far North, - based on the extensive use of the resource potential of the environment.

We would like to say separately about the development of oil and gas fields. The fact is that an analysis of the situation on the hydrocarbon market over the past few decades convinces us that the strategy chosen by Russia to expand the oil and gas sectors through the development of more and more new fields has not always proved itself to be successful. Price fluctuations, changing needs of the domestic and foreign markets, restrictions on 
production within the framework of decisions of interstate bodies, dumping policies of some countries (in particular, Saudi Arabia), economic sanctions - all this significantly reduces the profitability of these industries (especially export deliveries), far from complete least meeting expectations and invested funds. Taking into account the difficult recoverability of hydrocarbon resources in most areas, the cost of maintaining the infrastructure and means of delivery, losses during transportation of raw materials, and the profitability of some existing fields does not seem quite obvious. Add to this the environmental damage from frequent accidents, which is not always amenable to valuation.

In view of the foregoing, let us ask ourselves the question: is it worth it to spend a lot of money on banal drilling of next wells, the operation of which will not always bring profit, but is guaranteed to bring harm to the environment. Is it not better to use these funds to develop innovative technologies that will allow for deeper processing of hydrocarbons and reduce accident rate.

It seems that when planning the next "campaign for resources" answers to these questions would be appropriate.

Returning to the formation of the organizational and legal mechanism for ensuring environmental safety, we note that a significant step in this direction was the adoption of the Fundamentals of state policy in the field of environmental development of the Russian Federation for the period until 2030 (hereinafter - the Fundamentals). Having accepted the goals and principles of state policy in this area, as enshrined in earlier acts, the Fundamentals laid down mechanisms for their implementation, in accordance with clearly defined tasks: the formation of an effective management system in the field of environmental protection and environmental safety; improving the regulatory framework for environmental protection and environmental safety; ensuring environmentally oriented economic growth and the introduction of environmentally effective innovative technologies; prevention and reduction of the current negative impact on the environment; restoration of disturbed natural ecological systems; ensuring environmentally sound waste management; preservation of the natural environment, as well as the development of economic regulation and market-based instruments for its protection; creation of a modern system of state environmental monitoring, etc.

Implementation of the program provisions of the Fundamentals was Decree of the Government of the Russian Federation dated December 18, 2012 No. 2423-r "On approval of the Action Plan for the implementation of the Fundamentals of the state policy in the field of environmental development of the Russian Federation for the period until 2030", which contained a list of specific activities responsible for their implementation and terms of their implementation.

The regulatory documents considered by us played an important role in shaping the environmental policy of the Russian state, but did not allow forming a complete mechanism for ensuring environmental safety in our country. Many experts associated its final conceptual formation with the need to adopt an Environmental Safety Strategy. Such a document really appeared. On April 19, 2017, by a decree of the President of the Russian Federation, the Strategy for Environmental Safety of the Russian Federation for the period up to 2025 (hereinafter referred to as the Strategy) was approved, which today is the fundamental legal act in this area.

Describing the state of environmental safety in the country as extremely unfavorable, the Strategy set a goal - preservation and restoration of the natural environment, ensuring the quality of the environment necessary for a favorable human life and sustainable development of the economy, eliminating the accumulated environmental damage due to economic and other activities in the context of increasing economic activity and global climate change 
Compared with previously adopted regulatory documents, mechanisms for improving the quality of the environment are presented in more detail in the Strategy. The main attention is focused on the implementation of the best available technologies to reduce the negative impact of the anthropogenic factor on natural objects. It should be noted the instrumental innovation of the environmental safety mechanism contained in the Strategy indicators (indicators) of environmental safety, the list of which is quite detailed. Among them: the share of the territory of the Russian Federation that does not comply with environmental standards in the total area of the territory of the Russian Federation; the proportion of the population living in territories in which the state of the environment does not meet quality standards in the total population of the Russian Federation; the proportion of the population living in territories where the quality of drinking water does not meet sanitary standards in the total population of the Russian Federation, etc. All this testifies to the transformation of the system of regulation of these relations towards the transition from declarative statements to the establishment of specific criteria to assess the effectiveness of measures taken by the state. In turn, this allows us to hope for real shifts in the direction of improving the environmental situation in the country and achieving the main goal of the organizational and legal mechanism that we are studying - ensuring the environmental safety of citizens and the state.

\section{Conclusion}

Our brief analysis of the problem of ensuring environmental safety in Russia allowed us to draw the following conclusions:

- the lack of an integrated mechanism for ensuring global environmental safety transfers the burden of responsibility for the state of the environment to individual countries, forcing them to solve this problem at the national level and develop their own mechanisms for ensuring environmental safety. Moreover, the importance of domestic mechanisms in this area in a similar situation increases significantly, which is predetermined by the unity of the biosphere;

- The formation of the organizational and legal mechanism for ensuring environmental safety has been carried out in Russia for many years. During this time, our country has adopted a sufficient number of regulatory legal acts designed to solve this problem, however, the state of the environmental situation remains unsatisfactory. This is in contradiction with the tasks of the country's economic development, involving the active development of natural resources, including in territories not previously affected by economic activity. At the same time, a high degree of environmental vulnerability of these territories creates the possibility of an environmental catastrophe during the implementation of ill-conceived anthropogenic impact. This disaster can have global consequences, taking into account the importance of these territories as a natural reserve of the global ecosystem. All this actualizes the need to change existing economic approaches to the industrial development of territories, which should be reflected in the current environmental legislation;

- the organizational and legal mechanism for ensuring environmental safety in Russia is currently not yet perfect. In our opinion, the main reason for this lies in the absence of the majority of Russian citizens (including legislators) of a proper awareness of the depth of the environmental problem and its significance for the development prospects of society. This slows down the process of formation of effective legal instruments that allow translating the declared by the state priorities into the plane of practical activity. However, some changes in the legislative regulation of environmental safety issues inspire undoubted optimism. First of all, this concerns the establishment of specific indicators (indicators) of environmental safety, requirements for the introduction of new green technologies, etc .; 
- in general, Russia (as well as the rest of the world) needs a new mechanism of interaction with nature, based on maintaining the biosphere balance and the integrated perception of all factors that can upset this balance. Only such an approach will ensure our country sustainable development in conditions of reducing the ecological capacity of the natural environment and the need to build economic potential.

\section{References}

1. Federal Law of January 10, 2002 №7-FZ, Russian Newspaper, 6, 12, (2002)

2. The Constitution of the Russian Federation (Collection of the legislation of the Russian Federation, 31, 2 (2014)

3. N. Krupyshev, Ecological Congress on Neva, 4, 21, (2015)

4. Order of the Government of the Russian Federation of August 31, 2002 №1225-p, Russian newspaper, 176, 11 (2002)

5. T.V. Korchagina, G.V. Stas, D.O. Prokhorov, A.E. Koryakov, The state of the environment in the regions where mining is located, 4, 40-53 (2019)

6. V.P. Tkachev Risks of nature management of oil and gas producing regions of the North (Arctic), 2 (32), 210-215 (2015) 